\title{
Optimisation of Organic Solvent Mediated Solubilisation of Apple Pomace Polyphenolic Compounds Using Response Surface Methodologies
}

\author{
Salis Ibrahim ${ }^{1}$, Regina Santos ${ }^{2}$, Steve Bowra ${ }^{3}$ \\ ${ }^{1}$ University for Development Studies, PO Box TL 1350, Tamale, Ghana \\ ${ }^{2}$ University of Birmingham, Edgbaston, Birmingham, B15 2TT, UK \\ ${ }^{3}$ Department of Research and Development, Phytatec (UK) Ltd., Plas Gogerddan, Aberystwyth, SY23 3EB, UK \\ Correspondence: Salis Ibrahim, University for Development Studies, PO Box TL 1350, Tamale, Ghana. \\ E-mail: isalis@uds.edu.gh
}

Received: March 26, 2019 Accepted: May 5, 2019 Online Published: May 8, 2019

doi:10.5539/ijc.v11n2p1 URL: https://doi.org/10.5539/ijc.v11n2p1

\begin{abstract}
Polyphenolic compounds extraction from industrial apple pomace was optimised by applying design of experiments (DoE) and surface response methodology using the Central Composite Rotatable Design (CCRD). The degree solubilisation and the yield of total phenolic content from the apple pomace using organic solvents was shown to be influenced by process parameters including solvent type, solvent concentration, temperature, apple pomace to solvent ratio, and extraction time (residency time). Optimal conditions of extracting phenolic compounds were as follows: acetone concentration, $65 \%(\mathrm{v} / \mathrm{v})$; solid to solvent ratio $1 \%$; extraction time 30 minutes and temperature $60^{\circ} \mathrm{C}$. Optimum condition for solubilisation was as follows: acetone concentration $78 \%(\mathrm{v} / \mathrm{v})$; solid to solvent ratio $4.7 \%$; extraction time 54 minutes and temperature $21^{\circ} \mathrm{C}$. Under these conditions, the total phenolic content and solubilisation were $21.70 \pm 0.2 \mathrm{mg} \mathrm{GAE} / \mathrm{g} \mathrm{dw}$ and $19.20 \pm 0.1 \mathrm{~g} / 100 \mathrm{~g}$ of the dried apple pomace respectively and largely agreed with those predicted by the Stat-Ease software. Independent variables for optimisation of total phenolic content and solubilisation were completely different. The reverse phase HPLC analysis of the extract revealed the major polyphenolic compounds were chlorogenic acid, procyanidin B2, caffeic acid, epicatechin, ferulic acid, quercetin-3-galactoside, quercetin-3-glucoside and phloridzin.
\end{abstract}

Keywords: apple pomace, optimisation, polyphenolic compounds, solubilisation, response surface methodology

\section{Introduction}

Recent interest by researchers and nutraceutical manufacturers in polyphenolic compounds from fruit and vegetable sources have grown because of their potential antioxidant properties (Manach et al., 2004). The phytochemical extracts find applications in food, cosmetic and pharmaceutical industries (Cetkovic et al., 2008, Hunter and Hull, 1993, Lu and Foo, 1997, 2000, Vinson et al., 2001).

Recovery of the polyphenolic compounds from either fresh or dried fruit and vegetables sources was regarded as the number one step towards their application and could be extracted from samples (Dai and Mumper, 2010). Apples represent an important source of polyphenols in diets within Europe and the United States. Approximately $22 \%$ of flavonoids and phenolic acids consumed in the United states are derived from apples (Vinson et al., 2001). Polyphenolic compounds such as flavonoids, and phenolic acids represent non-nutrient natural compounds derived from fruits and vegetables and have been attributed to preventing diseases, control immune and inflammatory response, and protect against oxidation of lipids (Hollman et al., 1997, Liu, 2003). A strong inverse relationship exists between flavonoid intake and lung cancer development, which results in a reduction in the risk of lung cancer when associated with increased flavonoid consumption in younger people and in non-smokers (Knekt et al., 1997). The major phenolic compounds discovered in apple varieties include; Epicatechins, Procyanidins, Phloridzin, Quercetin conjugates and Chlorogenic acid (Bhushan et al., 2008).

The polyphenolic compounds in apples contribute to the colour and flavour of the fruit. Research have shown that, most of the polyphenolic compounds are restricted to the apple skin. Hence, the polyphenolic content in the apple peels is higher than that found in apple flesh and juice and varies among different cultivars of apples (Serena et al., 2007). Apple 
pomace, a by-product from apple juice and cider production is a heterogeneous biomass residue consisting of skin, discarded apples, seeds, core, stems and exhausted apple tissue (Kennedy et al., 1999). The biomass is wet and have varied levels of sugars and small amount of protein at a low pH (Chantanta et al., 2008). Therefore the isolations of the polyphenolic compounds by fractionating the biomass aligns with biorefining concept and at the same time generates valuable feedstock for food, feed, pharmacological or cosmetic purposes (Cetkovic et al., 2008, Lu and Foo, 1997, Lu and Foo, 2000). Polyphenolic compounds represent one of the diverse and extensively distributed class of substances in the plant kingdom with over 8000 chemical structures so far discovered (Harborne, 1993). The structure of phenolic compounds is made up of one or more hydroxyl groups fixed directly to an aromatic ring. Polyphenolic compounds on the other hand are compounds made up of at least, one phenolic group fixed to one or more aromatic rings (Crozier et al., 2006, Manach et al., 2004). Therefore, the term polyphenols do not refer to a polymer of simple phenols, and these compounds typically do not exist as free compounds in fruit and vegetable sources, but exist as glycoside or esters. Therefore, polyphenolics can vary from elementary compounds like phenolic acid to extremely polymerized molecules such as tannins. Primarily, the sugar residues are glucose but occasionally can be galactose, rhamnose, xylose and arabinose linked to the hydroxyl groups directly or otherwise (Laura et al., 2013).

The polyphenolic compounds fall in two classes 1) extractable (EP) and 2) non-extractable (NEP). Simple polar phenolic compounds such as hydrocinnamic acids and other flavonoids are easily extracted using organic solvents and therefore EPs dominate the scientific literature. Arranz et al., 2010, demonstrated that, non-extractable polyphenols are a major part of dietary polyphenols, therefore solely reporting extractable polyphenolics, underestimate the nutritional value of fruits and vegetables (Arranz et al., 2010, Saura-Calixto, 1998). Non-extractable polyphenols composed of polymeric polyphenols like proanthocyannidins and other cell wall bound polyphenolics. Non extractable polyphenolics found in extracts may account for the variation of total phenolic content of apple pomace reported in the literature (Bai et al., 2010, Reis et al., 2012, Suarez et al., 2010, Wijngaard and Brunton, 2010).

The main objective of the present study was to explore selectivity of aqueous organic solvents towards polyphenolic compounds, and at the same time optimise process parameters to maximise the recovery of the polyphenolics from apple pomace. Solubilisation based on the biomass (apple pomace) would be investigated to understand the relationship between soluble solids and total phenolic content recovered.

Response Surface Methodology (RSM) which is a collection of mathematical and statistical techniques employed to improve system performance for maximum benefits was explored to design the experiment. The RSM technique is widely applicable in chemical and biochemical processes to predict the behaviour of a response based on the set of independent variables by fitting a polynomial equation to the observed data from within a designed experiment.

\section{Material and Methods}

\subsection{Apple Pomace}

Apple pomace samples made up of 7 apple varieties (Michelin, Dabinett, Yarlinton Mill, Chisel Jersey, Brown Snout, Vilberie and Harry Masters Jersey) were collected from Universal Beverages Limited (UBL), Ledbury a subsidiary company of Bulmers, UK. The residues were thoroughly mixed to obtain representative mixture and divided into portions and stored at $-20^{\circ} \mathrm{C}$ until further analysis.

\subsection{Chemical Reagents}

All chemicals and standards utilised in this research where ordered from suppliers at the highest grade of purity outlined in the methods.

\subsection{Dry Weight Content of Apple Pomace}

The dry weight of the apple pomace was obtained using the AOCS (American Oil Chemist Society) standard procedure and expressed as the percentage of total wet weight of the apple pomace as received. A bench top laboratory convention oven $\left(103 \pm 3{ }^{\circ} \mathrm{C}\right)$ (STATUS International, UK) used to dry the material. Weight loss of apple pomace was monitored every 4 hours until no further change in weight was observed. Dried pomace was allowed to cool in a desiccator for 30 minutes to return to ambient conditions before reweighing.

\subsection{Preparation of Freeze Dried Apple Pomace}

Portions of the apple pomace were freeze dried using a vacuum freeze dryer (Model number EQ03 supplied by Vacuum and Industrial products). The pomace residue stored previously at $-20^{\circ} \mathrm{C}$ was loaded in the freeze dryer. Apple pomace samples were removed after complete drying and placed in desiccator for at least 30 minutes to return to ambient conditions. Moisture and dry weight content of the freeze dried pomace were determined as in AOCS (American Oil Chemist Society) standard procedure. The freeze dried apple pomace residue was then milled into a powder form using a domestic Moulinex blender 530 (KEMAEU, France). Apple pomace powder was packed in dark plastic bags and stored at room temperature for subsequent use. 


\subsection{Solvent Extraction of Polyphenolic Compounds from Apple Pomace}

Polyphenolic compounds were recovered from the freeze dried milled apple pomace under the solvent extraction using Max Q 4000 series benchtop shaker (Thermo Scientific). Known weight (according to solid-to-solvent ratio) of the freeze dried apple pomace powder was placed in 100ml Duran bottle and organic solvent (acetone or ethanol) was added and, the lid of the Duran bottle screwed tight and placed inside the incubator. Temperature for extraction were selected and confirmed by placing a thermometer inside of the incubator. Extraction time and shaking (150rpm) were set on the equipment. Shaking automatically stops when time for extraction has elapsed. extracts were immediately transferred into $50 \mathrm{ml}$ centrifuge tubes and centrifuged at $4000 \mathrm{~g}$ for 10 minutes using the Juan $\mathrm{C} 4 \mathrm{I}$ centrifuge. The volumes of supernatant were determined and clear extract stored at $-20{ }^{\circ} \mathrm{C}$. Extractions at higher temperatures $\left(60{ }^{\circ} \mathrm{C}\right.$ and $85^{\circ} \mathrm{C}$ ) were carried out similarly using a Grant OLS200 water bath.

\subsection{Determination of Biomass Solubilisation}

$1 \mathrm{ml}$ of clear extract was pipetted into pre-weighed dried Eppendorf tube and reweighed to obtain weight of wet sample. Sample were placed in the convention oven $\left(103 \pm 3{ }^{\circ} \mathrm{C}\right)$ to dry completely and the fraction of solubilisation in terms of dry weight of the starting material was obtained as in;

$$
\begin{aligned}
& \text { Fraction of solids solubilised } \\
& \qquad=\text { weight }\left(\frac{\text { solids }(\mathrm{g})}{\mathrm{ml}}\right) \times\left(\frac{\text { Total volume of extract }(\mathrm{ml})}{\text { weight of starting material }(\mathrm{g})}\right.
\end{aligned}
$$

\subsection{Total Phenolic Content Determination}

Apple pomace contains approximately 4.0\% proteins (Vasil'ev et al., 1976) which has the potential to interfere with total phenolic content determination in the extract (Singleton and Rossi, 1965). The proteins were removed from extract by measuring $80 \mu \mathrm{l}$ of the apple pomace extract into $2 \mathrm{ml}$ Eppendorf tube, followed by $120 \mu \mathrm{l}$ of the $100 \%(\mathrm{w} / \mathrm{v})$ Trichloroacetic Acid, TCA solution. Mixture was mixed thoroughly (Miximatic Vortex) before placing at $-20{ }^{\circ} \mathrm{C}$ for 5 minutes, and then $4{ }^{\circ} \mathrm{C}$ for 15 minutes. The Sample was then centrifuged at $15000 \mathrm{~g}$, at $4^{\circ} \mathrm{C}$ for 15 minutes using the Sigma k30 Laboratory centrifuge. The supernatants were transferred to fresh $2 \mathrm{ml}$ Eppendorf tubes. Any protein precipitate formed was separated. Total Phenolic Content (TPC) of all extracts were now determined using Folin-Ciocalteu micro-scale procedure already described by Waterhouse (Waterhouse, 2001). 20 $\mu \mathrm{l}$ of sample, standard and blank were pipetted into clean test tubes and then $1.58 \mathrm{ml}$ of distilled water added. Folin- Ciocalteu's phenol reagent, $100 \mu \mathrm{l}$ was then added and shaken to mix. $300 \mu$ of saturated Sodium Carbonate solution was then added and mixed thoroughly by Miximatic Vortex. Samples were left for 30 minutes at $40{ }^{\circ} \mathrm{C}$ in the Clifton unstirred water bath. After the incubation period, $300 \mu \mathrm{l}$ of the resulting solutions were pipetted into 96 Well F/B microplate and absorbance of standards/sample and blank read at 750nm using Promega Glomax Microplate Spectrophotometer. Total phenolic contents were expressed in terms of Gallic acid equivalent (GAE).

\subsection{Experimental Design}

Design of experiments for the solvent extraction techniques were composed of screening experiments and the actual design by response surface methodology (RSM). Screening experiments were conducted to identify effects of dependent variables on overall recovery of the bioactive compounds.

\subsubsection{Screening Experiments Under Organic Solvent Extraction}

The screening experiments utilised one factor at a time (OFAT), by changing one factor at a time whilst maintaining other factors constant. Solvent type, solvent concentration, solid- to- solvent ratio, temperature and extraction time were factors considered in the OFAT experiments.

The solvents acetone and ethanol were considered because they are generally recognized as safe (GRAS). The extractive capabilities using $60 \%(\mathrm{v} / \mathrm{v})$ of both solvents were investigated for consideration in the overall design. Solid-to solvent or loading ratio was fixed at 1:15, or 6.67\%, (Suarez et al., 2010), and extraction time of 3 hours at temperature $25^{\circ} \mathrm{C}$. Solvent extract with the highest Total phenolic value expressed in mg GAE /g dry weight of apple pomace was selected.

The effect of extraction time on recovery of polyphenolic compounds was investigated by employing the optimal solvent, $60 \%(\mathrm{v} / \mathrm{v})$ and varying time from 60 , through to 360 minutes whilst maintaining the temperature at $25^{\circ} \mathrm{C}$. Total phenolic contents of extracts were evaluated and optimal time selected based on the highest TPC on a mg GAE /g dry weight basis.

Using $60 \%(\mathrm{v} / \mathrm{v})$ of the optimal solvent, at a temperature of $25^{\circ} \mathrm{C}$ for optimised time of 60 minutes, the impact of loading (solid-to solvent ratio) was studied between $1-8 \%(\mathrm{w} / \mathrm{v})$. The solid-to-solvent which returned the maximum 
total phenolic content (mg/g) GAE dry weight basis was selected for further screening.

With the optimal solvent and solid-to-solvent ratio, at a fixed extraction temperature of $25{ }^{\circ} \mathrm{C}$ and for 60 minutes' residency time, extractions were carried out varying the concentration of solvent from $20 \%$ (v/v) through to 100\% (v/v) Solvent concentration with highest total phenolic content in $\mathrm{mg}$ GAE /g dry weight was used in subsequent investigation.

Lastly the effect of temperature on extraction of polyphenolic compounds was evaluated by varying the temperature from $25^{\circ} \mathrm{C}$ to $45^{\circ} \mathrm{C}$ while using the optimised independent variables.

\subsubsection{Experimental Design for Optimization of Solvent Extraction}

The results of the screening experiments were used, with the aid of Stat-Ease Design Expert software 7.0, to construct experiments using the central composite rotatable design (CCRD. Four design parameters (solid-to-solvent ratio, Solvent concentration, temperature and extraction time) were employed in the design to generate 30 experimental runs comprising of 16 trials for factorial points, 8 runs for axial points ( 2 for each of the 4 factors) and 6 replicates run around the centre points. The extraction programme is presented in Table 1 and design summary in Table 2. Response variables were, total phenolic content in $\mathrm{mg} \mathrm{GAE} / \mathrm{g} \mathrm{dw}$ and fraction of solids solubilised.

Table 1. Experimental design by Central Composite Rotatable using 4 factors under acetone extraction

\begin{tabular}{|c|c|c|c|c|c|}
\hline \multirow{3}{*}{$\begin{array}{l}\text { Standard } \\
\text { order }\end{array}$} & \multirow{3}{*}{$\begin{array}{l}\text { Run } \\
\text { order }\end{array}$} & Factor 1 & Factor 2 & Factor 3 & Factor 4 \\
\hline & & A: Acetone Conc. & B: Temp. & C: Solid/solvent ratio & D: Time \\
\hline & & $\%$ & ${ }^{\circ} \mathrm{C}$ & $\%$ & $\min$ \\
\hline 11 & 1 & 40.0 & 60.0 & 1.0 & 90.0 \\
\hline 21 & 2 & 60.0 & 35.0 & 1.0 & 60.0 \\
\hline 13 & 3 & 40.0 & 10.0 & 8.0 & 90.0 \\
\hline 9 & 4 & 40.0 & 10.0 & 1.0 & 90.0 \\
\hline 28 & 5 & 60.0 & 35.0 & 4.5 & 60.0 \\
\hline 7 & 6 & 40.0 & 60.0 & 8.0 & 30.0 \\
\hline 18 & 7 & 100.0 & 35.0 & 4.5 & 60.0 \\
\hline 5 & 8 & 40.0 & 10.0 & 8.0 & 30.0 \\
\hline 25 & 9 & 60.0 & 35.0 & 4.5 & 60.0 \\
\hline 17 & 10 & 20.0 & 35.0 & 4.5 & 60.0 \\
\hline 1 & 11 & 40.0 & 10.0 & 1.0 & 30.0 \\
\hline 15 & 12 & 40.0 & 60.0 & 8.0 & 90.0 \\
\hline 19 & 13 & 60.0 & 10.0 & 4.5 & 60.0 \\
\hline 22 & 14 & 60.0 & 35.0 & 11.5 & 60.0 \\
\hline 16 & 15 & 80.0 & 60.0 & 8.0 & 90.0 \\
\hline 23 & 16 & 60.0 & 35.0 & 4.5 & 5.0 \\
\hline 6 & 17 & 80.0 & 10.0 & 8.0 & 30.0 \\
\hline 26 & 18 & 60.0 & 35.0 & 4.5 & 60.0 \\
\hline 14 & 19 & 80.0 & 10.0 & 8.0 & 90.0 \\
\hline 4 & 20 & 80.0 & 60.0 & 1.0 & 30.0 \\
\hline 24 & 21 & 60.0 & 35.0 & 4.5 & 120.0 \\
\hline 12 & 22 & 80.0 & 60.0 & 1.0 & 90.0 \\
\hline 8 & 23 & 80.0 & 60.0 & 8.0 & 30.0 \\
\hline 30 & 24 & 60.0 & 35.0 & 4.5 & 60.0 \\
\hline 29 & 25 & 60.0 & 35.0 & 4.5 & 60.0 \\
\hline 20 & 26 & 60.0 & 85.0 & 4.5 & 60.0 \\
\hline 10 & 27 & 80.0 & 10.0 & 1.0 & 90.0 \\
\hline 2 & 28 & 80.0 & 10.0 & 1.0 & 30.0 \\
\hline 3 & 29 & 40.0 & 60.0 & 1.0 & 30.0 \\
\hline 27 & 30 & 60.0 & 35.0 & 4.5 & 60.0 \\
\hline
\end{tabular}

Table 2. Design summary under solvent extraction

\begin{tabular}{lllllll}
\hline Factor & Name & Units & Low & High & Mean & Std. Dev \\
\hline $\mathbf{A}$ & Acetone Conc. & $\%$ & 40 & 80 & 60 & 17.89 \\
B & Temperature & ${ }^{\circ} \mathrm{C}$ & 10 & 60 & 35.83 & 20.90 \\
$\mathbf{C}$ & Solid/Solvent & $\%$ & 1 & 8 & 4.62 & 2.99 \\
D & Time & min & 30 & 90 & 60.17 & 26.47 \\
\hline
\end{tabular}

All investigations were carried out in triplicates and results reported as mean \pm standard error. One-way analysis of variance (ANOVA) testing were conducted at 95\% confidence level. 


\subsection{Separation, Identification and Quantification of Phenolic Compounds by High Performance Liquid Chromatography (HPLC)}

Reverse phase high performance liquid chromatographic (HPLC) procedure previously described in literature was adopted (Schieber et al., 2001). Resolution of phenolic compounds in the extracts was performed using an Agilent 1100 series HPLC system with DAD-UV detector coupled to Chemstation software. Prodigy 5 $\mu \mathrm{m}$ ODS3 100A, C18 $(250 \mathrm{x}$ $4.6 \mathrm{~mm}$ I.D) column from Phenomenex (Torrance, CA, USA) was the stationary phase with a guard column operated at $40^{\circ} \mathrm{C}$.

The mobile phase consisted of $2 \%(\mathrm{v} / \mathrm{v})$ of the glacial acetic acid in water as eluent A. Eluent B was made with $0.5 \%$ of acetic acid in 50:50 (v/v) of water and acetonitrile. Eluent $\mathrm{C}$ was (100\%) acetonitrile. The gradient solvent systems programmed for the separation with a flow rate of $1 \mathrm{ml} / \mathrm{min}$ were as follows: beginning with $10 \%$ of $\mathrm{B}$ and increasing the gradient to $55 \%$ B in 50 minutes. Further increased from 55\% B to $100 \%$ B was done in 10 minutes and finally decreased from $100 \%$ B to initial 10\% B in 5 minutes. Eluent $C$ was used to recondition the column under isocratic flow by pumping $100 \% \mathrm{C}$ for 10 minutes, and $10 \% \mathrm{~B}$ also for 10 minutes. $10 \mu \mathrm{l}$ of samples were injected and phenolic compounds were monitored at $280 \mathrm{~nm}$ for flavanols, $320 \mathrm{~nm}$ for hydrocinnamic acid and $370 \mathrm{~nm}$ for flavonols. Retention time data was collected.

Phenolic standards comprising, Chlorogenic acid ( $\geq 95 \%)$, (-) Epicatechin ( $\geq 90 \%$ ), \pm Catechin hydrate, Phloridzin dihydrate ( $\geq 99 \%)$, Procyanidin B2 $(\geq 90 \%)$, Quercetin -3- $\beta$-D-glucoside $(\geq 90 \%)$, Quercetin-3-D-galactoside $(\geq 97 \%)$ Phloretin, Chromasolv for HPLC water purchased from Sigma-Aldrich (UK). Acetonenitrile, and glacial acetic acid were obtained from Fisher Scientific (UK). All reagents and chemicals used were either HPLC or analytical grade.

\section{Results and Discussion}

\subsection{Sample Preparation}

Correct and appropriate sample preparation was identified as a very important step to obtaining reproducible results. Therefore, maximum care was employed to minimise errors so as to achieve quality results. Apple pomace as received was very heterogeneous and composed of skins, seeds, apple flesh and calix, and therefore was thoroughly mixed to ensure replicate samples were representative of the pomace population. The mean dry weight content of the apple pomace sample received was $27.7 \pm 0.3 \mathrm{~g} / 100 \mathrm{~g}$ wet weight. Dry weight value reported for apple pomace reported in literature was 21.8 - $33.6 \mathrm{~g} / 100 \mathrm{~g}$ (Joshi and Attri, 2006, Kennedy et al., 1999, Sun et al., 2002).

Mean dry weight content of the freeze dried apple pomace was $28.3 \pm 0.6 \mathrm{~g} / 100 \mathrm{~g}$ fresh weight and therefore the residue was considered dried. Freeze drying method was chosen to stabilize apple pomace residue so as to retain the active ingredients like polyphenolics (Luthria, 2006).

\subsection{Screening Experiments under Organic Solvent Extraction}

Five factors were considered in the screening experiments to identify levels of influence or important in an overall experimental design. Selection was based on the factors which resulted in highest total phenolic content expressed as $\mathrm{mg} \mathrm{GAE} / \mathrm{g} \mathrm{dw}$.

\subsubsection{Organic Solvent Selection}

Efficiency of solvents in extraction of bioactive compounds depends strongly on the type of the plant material and has been reported in the literature (Dai and Mumper, 2010). The controlling parameter is the polarity of solvent in addition to the nature of the plant matrix. Polar solvents have higher efficiency to solubilise polar ingredients (Liyana-Pathirana and Shahidi, 2005). Polyphenolic compounds are polar and therefore easily eluted in highly polar solvents. Solvents such as methanol, ethanol and acetone have been employed to recover polyphenolics at room temperature from plant sources. Many researchers have used these solvents particularly with varying concentrations to extract polyphenolics from apple pomace (Cetkovic et al., 2008, Diñeiro García et al., 2009, Lu and Foo, 1999, Lu and Foo, 2000, Schieber et al., 2001, Suarez etal., 2010). Aqueous acetone 60\% (v/v) showed better recovery of phenolic compounds than corresponding aqueous ethanol as shown in Figure 1. 


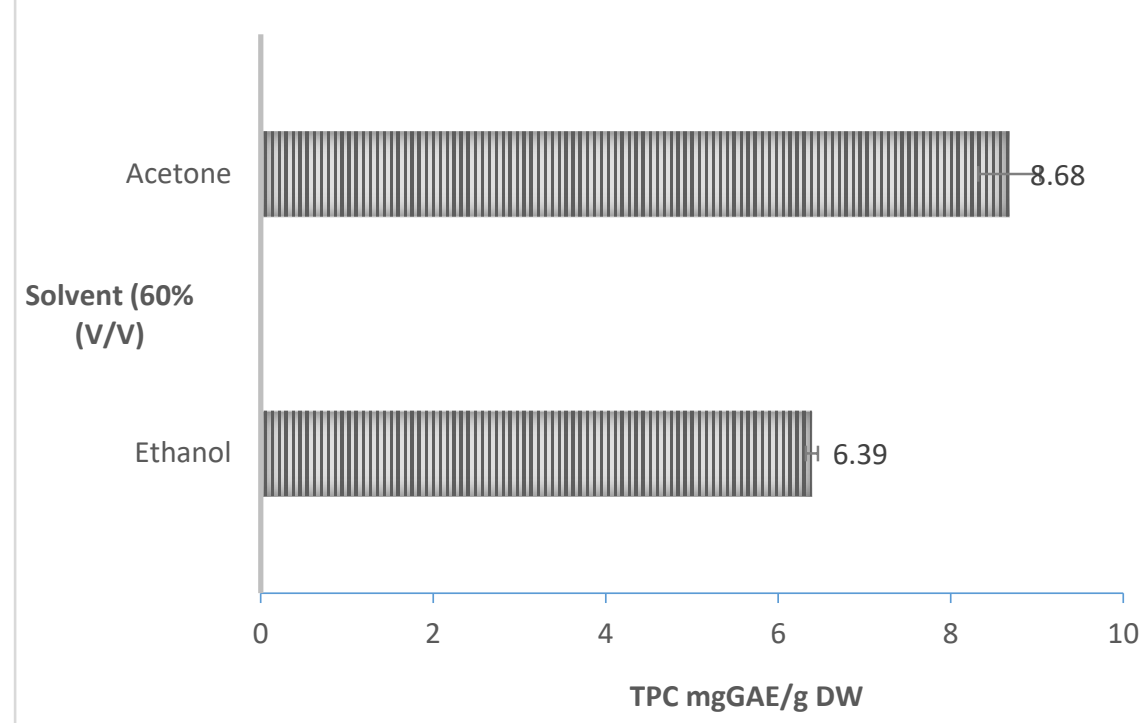

Figure 1. Solvent selection for recovery of polyphenolic compounds from apple pomace using $60 \%(\mathrm{v} / \mathrm{v})$ Ethanol and $60 \%(\mathrm{v} / \mathrm{v})$ acetone with solid to solvent ratio of $6.7 \%$ at $25^{\circ} \mathrm{C}$ for 360 minutes extraction time

The results was consistent with various reports that illustrated aqueous acetone exhibited a higher efficiency in term of extracting polyphenolics than aqueous ethanol (Heinonen et al., 1998, Kahkonen et al., 2001, Suarez et al., 2010). Acetone was regarded as a strong hydrogen bond breaker than ethanol (Hellström and Mattila, 2008). Total phenolic content of the aqueous acetone extract was approximately $26 \%$ higher than hydro ethanol extracts. $20 \%$ less of phenolic content in ethanol extract was achieved compared to acetone using apple pomace residue (Laura et al., 2013). The difference could be as a result of differences in the cultivars and also extraction procedures. Therefore, aqueous acetone was selected and used in the recovery of the polyphenolic compounds.

\subsubsection{Effect of Extraction Time}

The effect of extraction time on total phenolic content of apple pomace under screening experiment is presented in Figure 2.

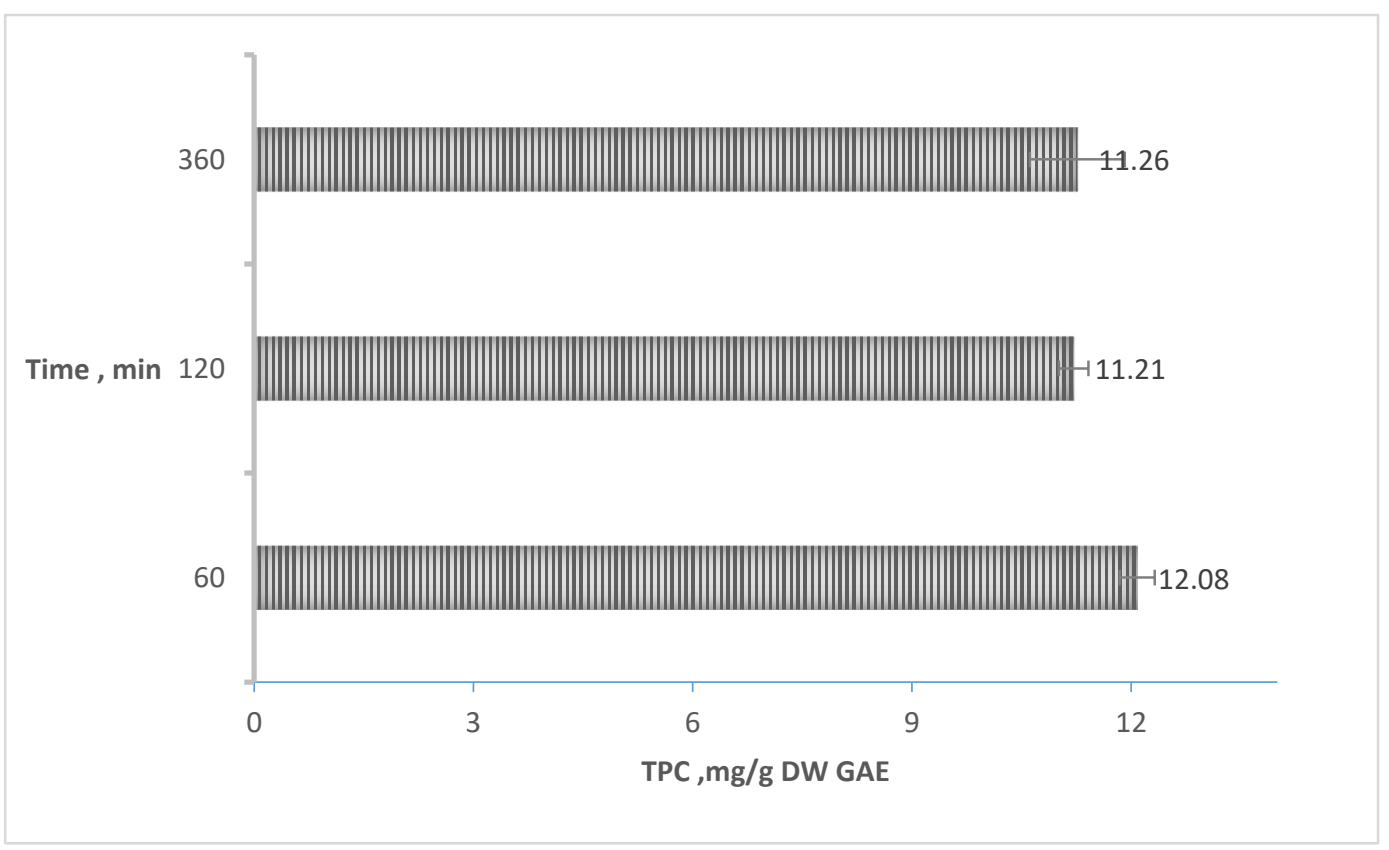

Figure 2. Effect of Extraction time (minutes') on recovery of polyphenolic compounds in terms of Total phenolic content (mg/g GAE DW) of apple pomace using $60 \%(\mathrm{v} / \mathrm{v})$ acetone concentration, $5 \%$. solid-to-solvent ratio at $25^{\circ} \mathrm{C}$

Total phenolic content at the 60 minutes was $12.08 \mathrm{mg}$ GAE /g dw, whereas for 120 minutes and 360 minutes were respectively $11.21 \mathrm{mg} / \mathrm{g}$ GAE DW and $11.26 \mathrm{mg} \mathrm{GAE} / \mathrm{g} \mathrm{dw}$ 
From the results shown above, there was no advantage of recovering polyphenolic compounds beyond 60 minutes. The decrease in total phenolic content ( $\mathrm{mg} \mathrm{GAE} / \mathrm{g} \mathrm{dw}$ ) could be due to oxidation of the phenolic compounds as a result of exposure to light for the extended time, in addition to reaction with dissolved oxygen in water (Silva et al., 2007). Phenolic compounds may also degrade or transformed to non oxidisable components, and may not react with the Folin reagent. Therefore 60 minutes was considered maximum extraction time for subsequent investigations. Further scanning using $60 \%(\mathrm{v} / \mathrm{v})$ acetone at $25^{\circ} \mathrm{C}$ confirms 60 minutes extraction time was better than 90 minutes as shown in Figure 3.

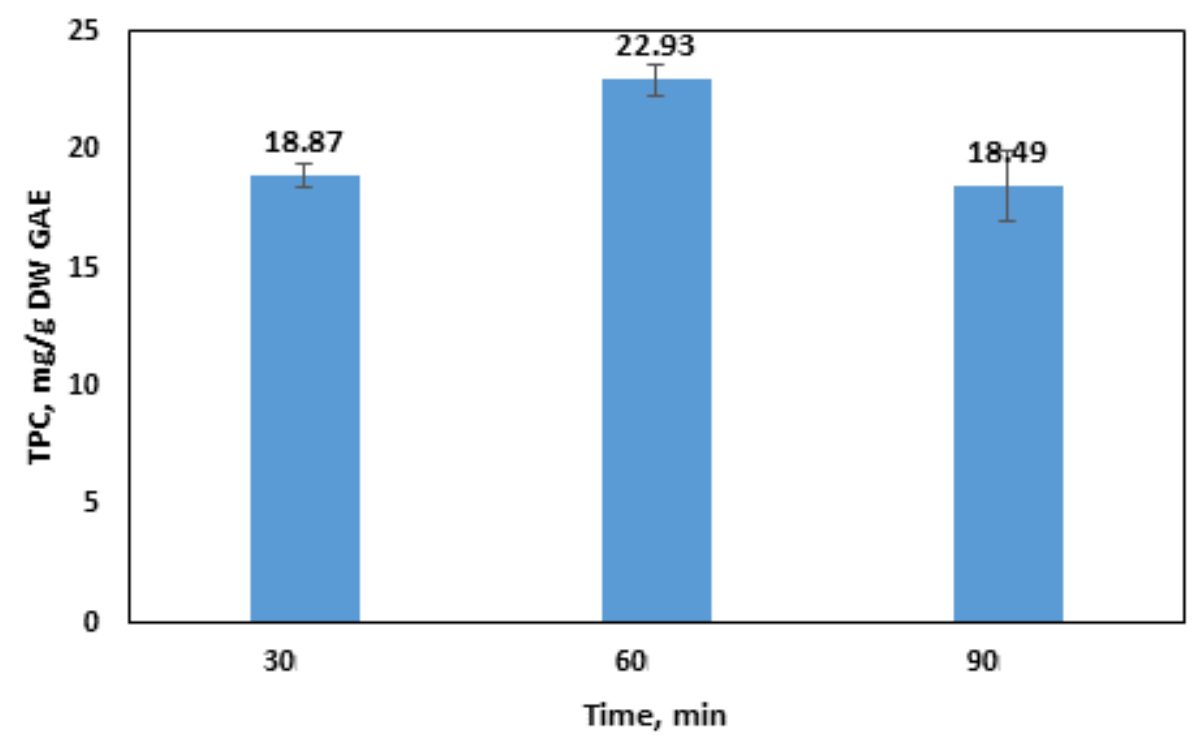

Figure 3. Effect of Extraction time (minutes) on Total phenolic content (mg GAE /g dw) of apple pomace using $60 \%(\mathrm{v} / \mathrm{v})$ acetone concentration, $1 \%$. solid-to-solvent ratio at temperature $25^{\circ} \mathrm{C}$

\subsubsection{Effect of Solid-to-Solvent Ratio}

The impact of solid-to-solvent ratio on total phenolic content from the freeze dried apple pomace powder using $60 \%$ (v/v) acetone for an extraction time of 60 minutes at $25^{\circ} \mathrm{C}$, is shown in Figure 4.

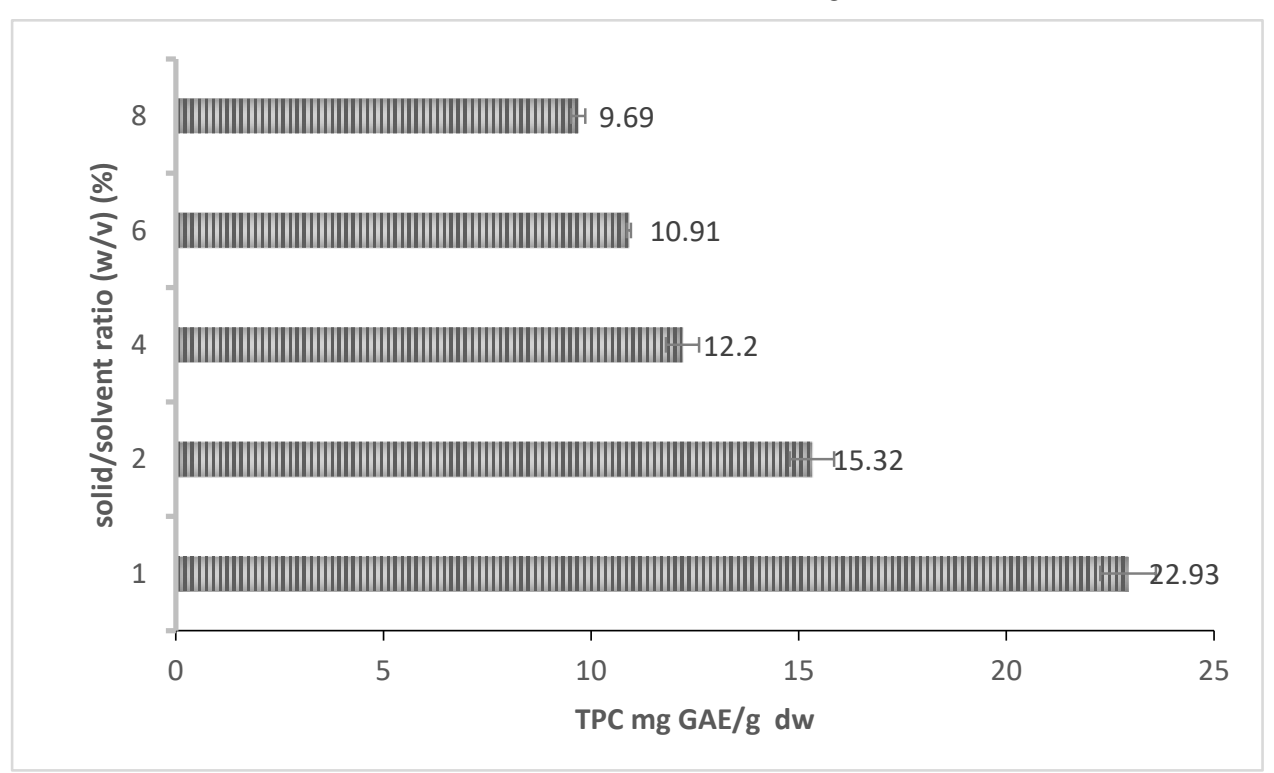

Figure 4. Effects of solid-to-solvent ratio \% (w/v) on Total phenolic content (mg GAE /g dw) of apple pomace using $60 \%(\mathrm{v} / \mathrm{v})$ acetone concentration, at temperature $25^{\circ} \mathrm{C}$ for 60 minutes' extraction time

Total phenolic content decreases as the ratio of solid to solvent increases. Total phenolic content of $1 \%$ was $22.93 \mathrm{mg}$ $\mathrm{GAE} / \mathrm{g} \mathrm{dw}$ and for $8 \%$ it was $9.69 \mathrm{mg} \mathrm{GAE} / \mathrm{g} \mathrm{dw}$. The results showed better mass transfers were observed in the lower loadings thereby giving higher amounts of polyphenolic compounds. 
Higher loading ratios may result to incomplete extraction due to insufficient amount of solvent (Cruz et al., 2013). Therefore $1 \%$ solid-to-solvent ratio was considered as the lower limit and the $8 \%$ as the higher limits to study how the influence of other parameters will impact total phenolic content. One of the most important goals of industry was to optimise operating cost to achieve higher output and increasing loading rate (Klein-Marcuschamer et al., 2011).

\subsubsection{Effect of Solvent Concentration}

The effect of the acetone concentration on the polyphenolic recovery is shown in Figure 5.

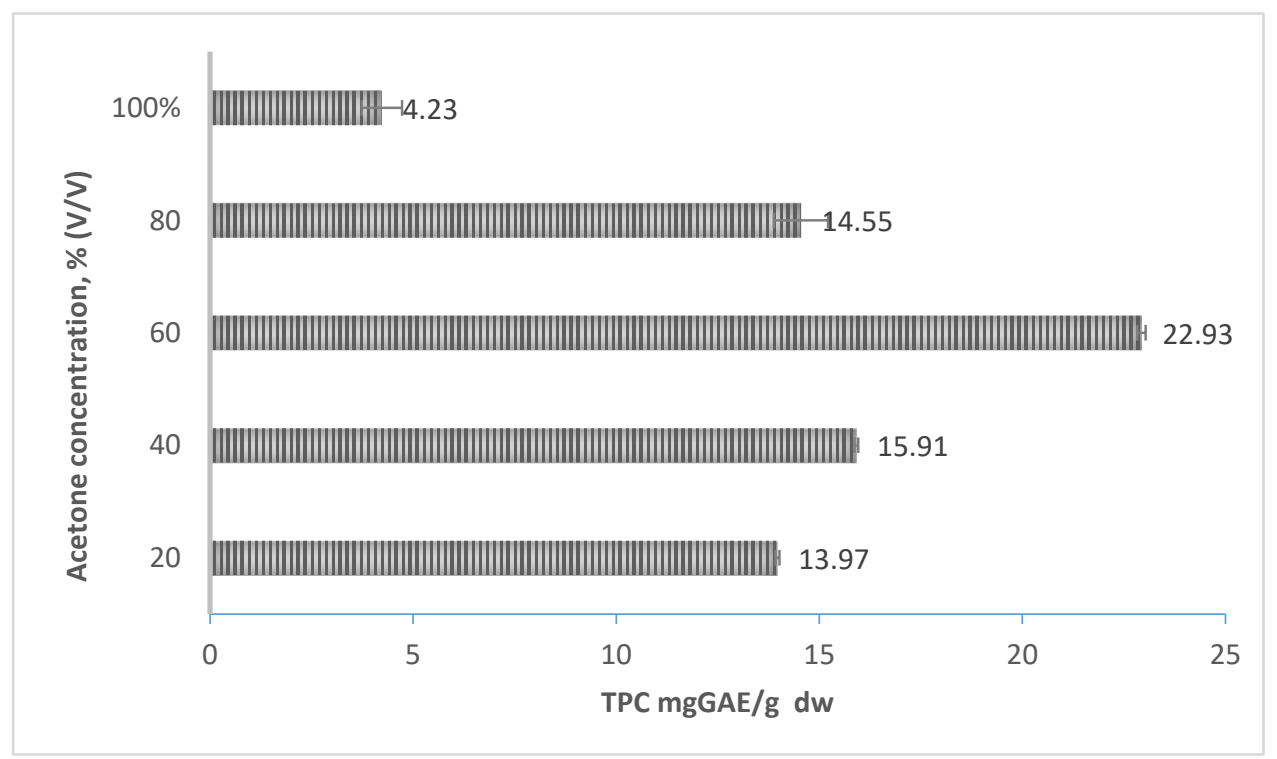

Figure 5. Effect of acetone concentration \%(v/v) on Total phenolic content (mg GAE /g dw) of apple pomace using $1 \%$ solid -to -solvent ratio at temperature $25^{\circ} \mathrm{C}$ for an extraction time of 60 minutes

From the graph total phenolic content increases from $20 \%(\mathrm{v} / \mathrm{v})$ acetone concentration to $60 \%(\mathrm{v} / \mathrm{v})$ and decreases thereafter. $60 \%(\mathrm{v} / \mathrm{v})$ acetone was the optimal solvent concentration in this comparison with total phenolic content of $22.93 \mathrm{mg} \mathrm{GAE} / \mathrm{g} \mathrm{dw}$, suggesting that, addition of water improved the polarity of acetone and hence its efficiency. However, too much water couldn't enhance recovery of phenolic compounds as shown in $20 \%(\mathrm{v} / \mathrm{v})$ acetone concentration recording approximately $14 \mathrm{mg}$ GAE /g dw. Total phenolic content decreased above $60 \%(\mathrm{v} / \mathrm{v})$ acetone concentration and to a low value of $4.23 \mathrm{mg} / \mathrm{g} \mathrm{GAE} \mathrm{DW}$ at $100 \%(\mathrm{v} / \mathrm{v})$. The results showed that pure or total acetone demonstrated poor recovery of antioxidant compounds from the apple pomace. Low efficacy of pure acetone in extracting polyphenolic compounds from plant material have been reported (Chen et al., 2007, Liyana-Pathirana and Shahidi, 2005). Hence $40 \%(\mathrm{v} / \mathrm{v})$ and $80 \%(\mathrm{v} / \mathrm{v})$ of acetone were selected as the lower and upper limits respectively in designing the experiments.

\subsubsection{Effect of Temperature on Extraction}

Total phenolic content of extracts of the screening experiments did not vary significantly from $25^{\circ} \mathrm{C}$ to $45^{\circ} \mathrm{C}$ suggesting that temperature has minimal effect on the extraction of polyphenolic compounds within the range as shown in Figure 6. 


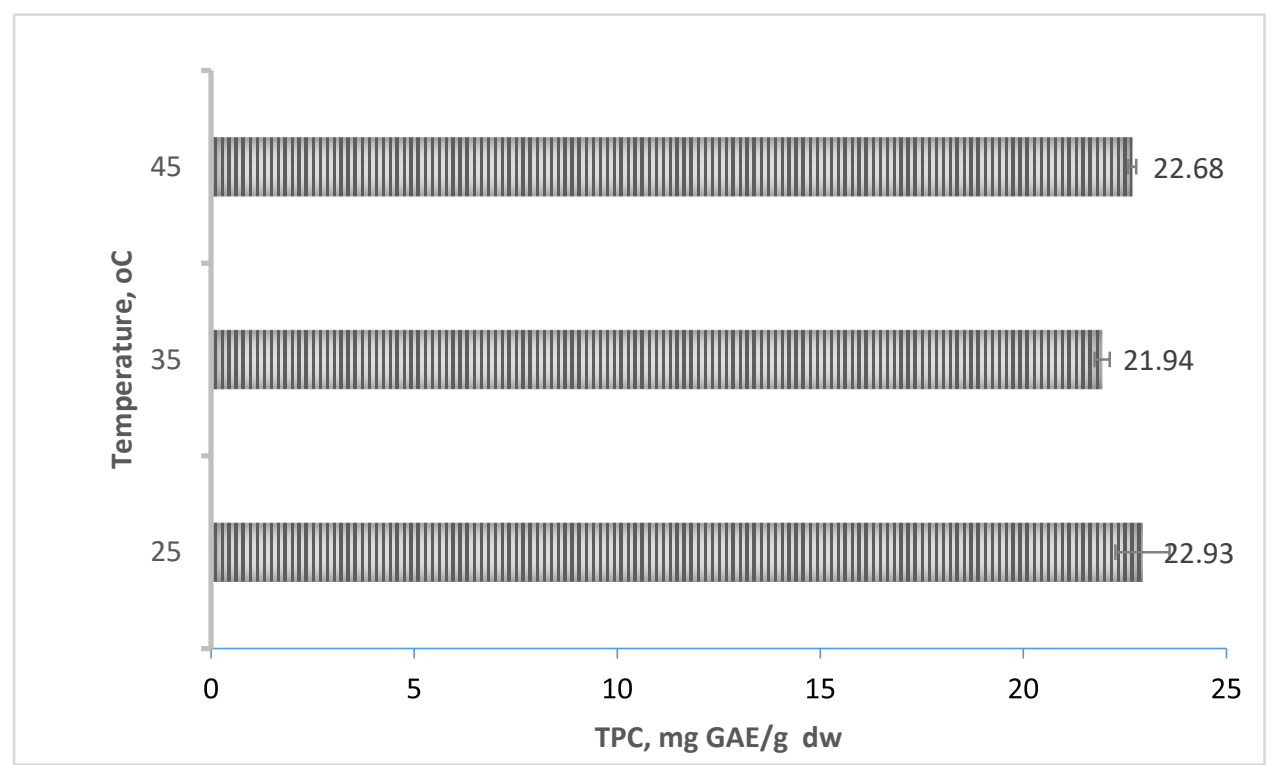

Figure 6. Effect of temperature $\left({ }^{\circ} \mathrm{C}\right)$ on Total Phenolic content (mg GAE /g dw) of apple pomace using $60 \%(\mathrm{v} / \mathrm{v})$ acetone concentration, $1 \%$ solid to solvent ratio for 60 minutes' extraction time

Increasing temperature generally enhances solubility and diffusion rates which promote effective mass transfer to results in higher recoveries. Increase in temperature of solvent lowers its surface tension and viscosity which enhances its percolation around sample matrixes resulting in higher yields of extract (Dai and Mumper, 2010). However this was not observed for the selected (solid/solvent) ratio of $1 \%$ where the solid matrix would have been well saturated with more than enough solvent and changes in temperature would have very minimal effect on overall recovery of phenolic compounds. The ANOVA results shows that there was no difference between the total phenolic content of extracts at 25 ${ }^{\circ} \mathrm{C}, 35^{\circ} \mathrm{C}$ and $45^{\circ} \mathrm{C} \quad(\mathrm{p}<0.05)$. Therefore temperatures of $10^{\circ} \mathrm{C}$ and $60{ }^{\circ} \mathrm{C}$ were employed as lower and upper limits in designing the experiments.

\subsection{General Consideration for Model Selection}

Several model options including linear, two factor interaction and polynomial models were investigated for selection of most appropriate one that will be able to depict real time response

of the surface. Statistical analysis of variance (ANOVA) was performed on the experimental data using the Stat-Ease Design Expert to select the model. For a given model should be to significant and the lack of fit insignificant. Additionally, the proposed models were compared based on adjusted $\mathrm{R}^{2}$ and predicted $\mathrm{R}^{2}$. It is very important not to measure the success of the regression analysis based on the coefficient of determination $\mathrm{R}^{2}$ alone, which is the calculation of the "variation explained by the model relative to the mean (overall, average of response)". The caution that " don't let $\mathrm{R}^{2}$ value fool you" (Hair et al., 1995) was adhered to. The quadratic model was appropriate among the rest and follows a generalised second order polynomial equation as in;

$$
\mathrm{y}=\beta_{0}+\sum_{i=1}^{4} \beta_{i} x_{i}+\sum_{i=1}^{4} \beta_{i i} x_{i}^{2}+\sum \sum_{i<j=1}^{4} \beta_{i j} x_{i} x_{j}
$$

In developing a good model, the simplest one is most favoured and to resolve this, may require removing outliers and transforming of the selected quadratic models.

\subsubsection{Model Selection for Total Phenolic Content and Fraction of Solids Solubilised under Solvent Extraction}

Total phenolic content ranged from $6.99 \mathrm{mg} / \mathrm{g} \mathrm{dw}$ GAE to $22.55 \mathrm{mg}$ GAE /g dw with mean phenolic content of 12.42 $\mathrm{mg}$ GAE /g dw. By subjecting the experimental data to multiple regression analysis, at $95 \%$ confidence interval, a transformed quadratic equation excluding outliers in the analysis was selected. The model was based on most influential design parameter, solid-to solvent ratio which varies with Total phenolic content as a single factor as in Figure 7. 


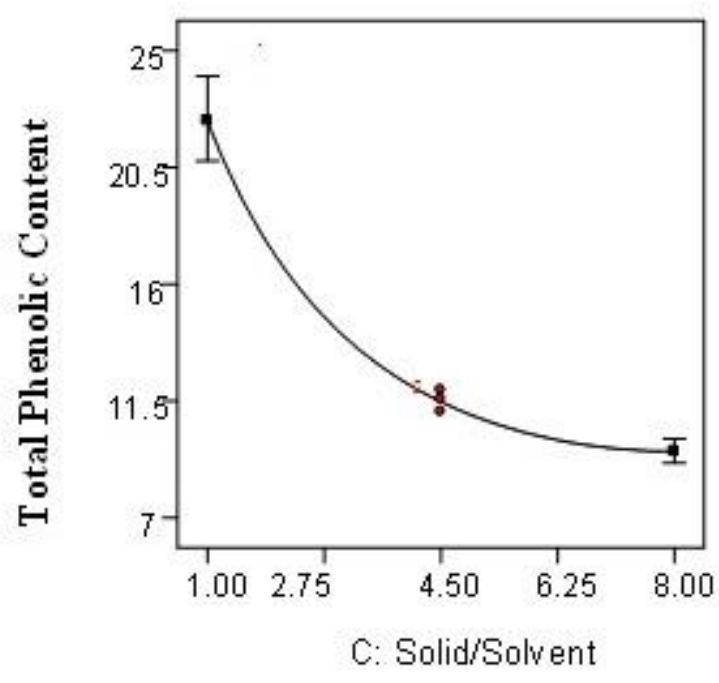

Figure 7. Variation of Total phenolic with Solid/Solvent ratio of apple pomace using $60 \%(\mathrm{v} / \mathrm{v})$ acetone concntration, at temperature $25^{\circ} \mathrm{C}$ for 60 minutes' extraction time

The transformed generalised second order polynomial model equation is shown below;

$$
\frac{1}{\sqrt{y}}=\beta_{0}+\sum_{i=1}^{4} \beta_{i} x_{i}+\sum_{i=1}^{4} \beta_{i i} x_{i}^{2}+\sum \sum_{i<j=1}^{4} \beta_{i j} x_{i} x_{j} .
$$

Where, $\beta_{0} \beta_{i} \beta_{i i}$ and $\beta_{i j}$ are the respective coefficient of regression for intercept, linear, quadratic and interaction terms. $x_{i}$ and $x_{j}$ are coded design variables. Results for the Analysis of variance (ANOVA) for the response surface of the reduced quadratic model are shown in Table 3.

Table 3. ANOVA for Response Surface Reduced Quadratic Model for TPC under Solvent Extraction

\begin{tabular}{|c|c|c|c|c|c|}
\hline Source & $\begin{array}{l}\text { Sum } \\
\text { of } \\
\text { Squares }\end{array}$ & $\mathrm{df}$ & $\begin{array}{l}\text { Mean } \\
\text { Square }\end{array}$ & $\begin{array}{l}\mathrm{F} \\
\text { Value }\end{array}$ & $\begin{array}{l}\mathrm{p} \\
\text { value }\end{array}$ \\
\hline Model & 0.051 & 7 & $7.217 \times 10^{-3}$ & 49.70 & $<0.0001$ \\
\hline$A$ & $2.649 \times 10^{-4}$ & 1 & $2.649 \times 10^{-4}$ & 1.82 & 0.1945 \\
\hline \multicolumn{6}{|l|}{ Acetone Conc } \\
\hline$B$ & $1.357 \times 10^{-3}$ & 1 & $1.357 \times 10^{-3}$ & 9.35 & 0.0071 \\
\hline \multicolumn{6}{|l|}{ Temperature } \\
\hline C & 0.042 & 1 & 0.042 & 288.76 & $<0.0001$ \\
\hline \multicolumn{6}{|l|}{ Solid/solvent } \\
\hline$D$ & $1.054 \times 10^{-4}$ & 1 & $1.054 \times 10^{-4}$ & 0.73 & 0.4060 \\
\hline \multicolumn{6}{|l|}{ Time } \\
\hline$C D$ & $7.659 \times 10^{-4}$ & 1 & $7.6659 \times 10^{-4}$ & 5.27 & 0.0346 \\
\hline$A^{2}$ & $4.392 \times 10^{-3}$ & 1 & $4.392 \times 10^{-3}$ & 30.86 & $<0.0001$ \\
\hline$C^{2}$ & $4.481 \times 10^{-3}$ & 1 & $4.481 \times 10^{-3}$ & 30.86 & $<0.0001$ \\
\hline Residual & $2.468 \times 10^{-3}$ & 17 & $1.452 \times 10^{-4}$ & & \\
\hline Lack of Fit & $1.263 \times 10^{-3}$ & 12 & $1.053 \times 10^{-4}$ & 0.44 & 0.8886 \\
\hline Pure Error & $1.205 \times 10^{-3}$ & 5 & $2.410 \times 10^{-4}$ & & \\
\hline Cor Total & 0.053 & 24 & & & \\
\hline
\end{tabular}


Solid/solvent was the most significant factor among the independent variables within the experimental range and has probability values for both the linear and quadratic terms, $(p<0.0001)$. Acetone concentration was significant only in the quadratic term $(\mathrm{p}<0.0001)$. Interaction between solid-to-solvent ratio and time was significant $(\mathrm{p}=0.0346)$.

However, temperature effects was significant $(\mathrm{P}=0.0071)$ within the selected range contrary to observation in the screening experiment and in the optimisation of antioxidant compounds from apple pomace by response surface methodology (Wijngaard and Brunton, 2010). A response surface methodology using a Box-Behnken design for the optimisation of polyphenols from apple pomace by micro-wave assisted extraction method by Bai and co-workers revealed that, total phenolic content followed a normal quadratic and depended on the solid to solvent ratio in addition to microwave power, solvent concentration and extraction time (Bai et al., 2010). The range of solid to solvent ratio was between $1: 10$ and 1:30 in their investigation compared to a ratio of $1: 12.5$ to $1: 100$ (8\% to $1 \% \mathrm{w} / \mathrm{v})$ in this current research. This justifies why a transformed quadratic model was suitable, simple and meaningful which was highly leveraged by the total phenolic content, and significantly depended on the loading of the biomass. Extraction time within the selected range was not significant $(\mathrm{P}=0.4060)$, meaning 30 minutes was enough to have recovered phenolic compounds from the apple pomace. The contribution of the centrifugation process to extraction phenomenon may be compensating for the overall recovery yield and time of extraction. From the regression analysis it was shown that selected model was highly significant $(\mathrm{P}<0.0001)$ and lack of fit is insignificant $(\mathrm{p}>0.1)$. Additionally, the predicted $\mathrm{R}^{2}$ value of 0.9096 reasonable agrees to the adjusted $\mathrm{R}^{2}$ value of 0.9342 with a low coefficient of variation of $4.07 \%$ suggesting a high level of precision and reliability of measured values as shown in Table 4.

Table 4. Adequacy Level for Response Surface Reduced Quadratic Model for TPC under Solvent Extraction.

$\begin{array}{llcl}\text { Std. Dev. } & 0.0 .12 & R^{2} & 0.9534 \\ \text { Mean } & 0.30 & R_{\text {Adj }}^{2} & 0.9342 \\ \text { C.V. \% } & 4.07 & R_{\text {Pri }}^{2} & 0.9096 \\ \text { PRESS } & 4.790 \times 10^{-3} & \text { Precision } & 22.133\end{array}$

Adequate precision defined as 'the ratio of signal to noise ratio' 'of this analysis was 22.133 which was good as a ratio greater than 4 is usually preferred. Hence this model can be used to navigate the design space. Final estimates for the intercept, linear and quadratic terms at 95\% confidence interval are shown in Table 5.

Table 5. Coefficients Estimates terms for Reduced Quadratic Model for TPC under Solvent Extraction.

\begin{tabular}{|c|c|c|c|c|c|c|}
\hline Factor & $\begin{array}{l}\text { Coefficient } \\
\text { Estimate }\end{array}$ & $\mathrm{df}$ & $\begin{array}{l}\text { Standard } \\
\text { Error }\end{array}$ & $\begin{array}{l}95 \% \text { CI } \\
\text { Low }\end{array}$ & $\begin{array}{l}95 \% \text { CI } \\
\text { High }\end{array}$ & $\begin{array}{l}\text { VI } \\
\text { F }\end{array}$ \\
\hline Intercept & 0.30 & 1 & $4.075 \times 10^{-3}$ & 0.29 & 0.30 & \\
\hline$A$ & $-3.523 \times 10^{-3}$ & 1 & $2.609 \times 10^{-3}$ & $-9.028 \times 10^{-3}$ & $1.981 \times 10^{-3}$ & 1.02 \\
\hline$B$ & $-8.598 \times 10^{-3}$ & 1 & $2.812 \times 10^{-3}$ & -0.015 & $-2.664 \times 10^{-3}$ & 1.03 \\
\hline C & 0.056 & 1 & $3.283 \times 10^{-3}$ & 0.049 & 0.063 & 1.03 \\
\hline$D$ & $2.487 \times 10^{-3}$ & 1 & $2.919 \times 10^{-3}$ & $-3.671 \times 10^{-3}$ & $8.646 \times 10^{-3}$ & 1.05 \\
\hline$C D$ & $7.529 \times 10^{-3}$ & 1 & $3.278 \times 10^{-3}$ & $6.126 \times 10^{-4}$ & 0.014 & 1.04 \\
\hline$A^{2}$ & 0.013 & 1 & $2.361 \times 10^{-3}$ & $8.004 \times 10^{-3}$ & 0.18 & 1.02 \\
\hline$C^{2}$ & -0.028 & 1 & $4.965 \times 10^{-3}$ & -0.038 & -0.017 & 1.05 \\
\hline
\end{tabular}

Note: $\mathrm{A}=$ acetone concentration $(\% \mathrm{v} / \mathrm{v}), \mathrm{B}=$ Temperature $\left({ }^{\circ} \mathrm{C}\right), \mathrm{C}=$ solid-to- solvent ratio, $(\% \mathrm{w} / \mathrm{v})$ and $\mathrm{D}=$ extraction time (minutes).

Coefficient estimates for acetone concentration was $-3.523 \times 10^{-3}$ of post ANOVA analysis at $95 \%$ confidence and a Variance inflation factor (VIF) of 1.02. Variance inflation factor is an estimation of how much of the variance of a coefficient was inflated because of linear dependence with other predictors. This factor has a lower bound value of 1 with several recommended upper bound values reported in literature. Maximum level of 10 (Hair et al., 1995), 5 (Rogerson, 2001), 4 (Park and Jackson, 2008) and 2.5 (Allison, 2012) have been recommended. Lower levels of VIF are desired because higher levels constitute a problem and affect results in multiple regression analysis (Allison, 2012). Variance inflation factor of acetone concentration of 1.02 means the coefficient was larger than a factor 1.02 than would otherwise be if there were no intercorrelations between total phenolic content, solid-to solvent ratio, temperature and time. Variances of all coefficients in the model were not very much inflated as the highest value of 1.05 in the model was just close to the minimum VIF of 1.0. 
Negative values of any coefficient suggest a certain maximum value beyond which total phenolic content will decrease significantly. Therefore, increasing, acetone concentration, solid-to-solvent ratio and temperature arbitrary may not favour overall yield of polyphenolic compounds in extract. Higher loading of solids relative to solvent reduced effective mass transfer and higher temperature may lead to decomposition of polyphenolic compounds originally accumulated around low temperatures regions. Degradation of phenolic compounds under high temperatures in solvent extraction had previously been reported (Hismath et al., 2011, Pacheco-Palencia et al., 2009).

The final model equation for TPC in terms of actual factors is shown below;

$$
\begin{aligned}
& \frac{1}{\sqrt{T P C}} \\
& =+0.33175-4.07195 \times 10^{-3} A-3.43929 \times 10^{-4} B+0.031902 C-2.39748 \times 10^{-4} D+7.17020 \\
& \times 10^{-5} C D+3.24648 \times 10^{-5} A^{2}-2.25179 \\
& \times 10^{-3} C^{2}
\end{aligned}
$$

Where $A, B, C, D$ and $T P C$ represent Acetone concentration, temperature solid/solvent ratio, extraction time and total phenolic content respectively.

Similar rigorous procedures for selecting appropriate model were pursued for fraction of solids solubilised per 100g of the apple pomace and it followed a reduced quadratic model. The fraction of solids solubilised in all extracts ranges from $9.7 \mathrm{~g} / 100 \mathrm{~g}$ to $19.4 \mathrm{~g} / 100 \mathrm{~g}$ with a mean value of $16.23 \mathrm{~g} / 100 \mathrm{~g}$ of the dried apple pomace.

The proposed model was significant $(\mathrm{p}<0.0001)$ and an insignificant lack of fit $(\mathrm{p}=0.6319)$. Overall regression coefficient was 0.9506 and $R_{A d j}^{2}(0.9163)$ with undefined $R_{P r i}^{2}$ and predictive residual sum of squares (PRESS) because the leverage in the analysis was 1.00 . Coefficient of variation was $4.65 \%$ and all variances of the coefficients were inflated by less than 1.5. The final equation in terms of actual factors is;

$$
\begin{gathered}
\mathrm{FSS}=-2.48025-0.082150 A+0.033668 B+0.88060 C+0.59345 D-0.010155 \mathrm{AC}+5.69564 \times 10^{-3} B C \\
-1.10062 \times 10^{-3} \mathrm{BD}+1.63244 \times 10^{-3} A^{2}-4.65261 \times 10^{-3} B^{2}
\end{gathered}
$$

In this case $A, C, A C, B C, B D, A^{2}, D^{2}$ are significant model terms $(\mathrm{P}<0.05)$

An evaluation of the predictive effects of the models for total phenolic and fraction of solids solubilised are shown in Tables 6 and 7. The models were only approximations and does not represent the actual and can't be relied upon predictions outside the limits of the design factors. It was only good enough to give an idea or direction (Shari, 2013). 
Table 6. Actual total phenolic content vs predicted (mg GAE /g dw)

\begin{tabular}{|c|c|c|c|}
\hline $\begin{array}{l}\text { Standard } \\
\text { order }\end{array}$ & Sample & $\begin{array}{l}\text { Actual TPC } \\
(\mathrm{mg} \mathrm{GAE} / \mathrm{g} \mathrm{dw})\end{array}$ & $\begin{array}{l}\text { Predicted TPC } \\
(\mathrm{mg} \mathrm{GAE} / \mathrm{g} \mathrm{dw})\end{array}$ \\
\hline 1 & $40-10-1-30$ & 17.47 & 17.36 \\
\hline 2 & $80-10-1-30$ & 17.73 & 18.90 \\
\hline 3 & $40-60-1-30$ & 19.58 & 18.90 \\
\hline 5 & $40-10-8-30$ & 8.90 & 8.65 \\
\hline 6 & $80-10-8-30$ & 8.90 & 8.65 \\
\hline 7 & $40-60-8-30$ & 9.90 & 9.18 \\
\hline 8 & $80-60-8-30$ & 9.87 & 9.18 \\
\hline 9 & $40-10-1-90$ & 21.68 & 17.36 \\
\hline 11 & $40-60-1-90$ & 19.25 & 18.90 \\
\hline 12 & $80-60-1-90$ & 22.55 & 20.66 \\
\hline 14 & $80-10-8-90$ & 8.74 & 8.65 \\
\hline 15 & $40-60-8-90$ & 8.30 & 9.18 \\
\hline 16 & $80-60-8-90$ & 9.36 & 9.18 \\
\hline 17 & $20-35-4.5-60$ & 8.14 & 8.65 \\
\hline 18 & $100-35-4.5-60$ & 8.46 & 8.65 \\
\hline 19 & $60-10-4.5-60$ & 10.13 & 11.11 \\
\hline 20 & $60-85-4.5-60$ & 14.03 & 14.79 \\
\hline 21 & $60-35-1-60$ & 15.32 & 18.90 \\
\hline 22 & $60-35-11.5-60$ & 9.27 & 9.77 \\
\hline 23 & $60-35-4.5-5$ & 6.99 & 10.41 \\
\hline 24 & $60-35-4.5-120$ & 10.95 & 10.41 \\
\hline 25 & $60-35-4.5-60$ & 13.31 & 10.41 \\
\hline 26 & $60-35-4.5-60$ & 11.92 & 10.41 \\
\hline 27 & $60-35-4.5-60$ & 11.08 & 10.41 \\
\hline 28 & $60-35-4.5-60$ & 11.57 & 10.41 \\
\hline 29 & $60-35-4.5-60$ & 9.69 & 10.41 \\
\hline 30 & $60-35-4.5-60$ & 11.85 & 10.41 \\
\hline
\end{tabular}


Table 7. Experimental and predicted values of fraction of solids solubilised (g/100g) of starting material under different extraction conditions

\begin{tabular}{cccc}
\hline Standard Order & $\begin{array}{c}\text { Experimental } \\
\text { condition }\end{array}$ & Actual Value $(\mathrm{g} / 100 \mathrm{~g})$ & Predicted Value $(\mathrm{g} / 100 \mathrm{~g})$ \\
\hline 1 & $40-10-1-30$ & 10.00 & 11.00 \\
2 & $80-10-1-30$ & 15.40 & 15.14 \\
4 & $80-60-1-30$ & 15.40 & 15.46 \\
5 & $40-10-8-30$ & 15.50 & 14.72 \\
6 & $80-10-8-30$ & 16.00 & 16.02 \\
7 & $40-60-8-30$ & 16.40 & 17.03 \\
8 & $80-60-8-30$ & 19.00 & 18.33 \\
9 & $40-10-1-90$ & 13.30 & 12.45 \\
11 & $40-60-1-90$ & 9.70 & 9.46 \\
12 & $80-60-1-90$ & 13.50 & 13.61 \\
13 & $40-10-8-90$ & 16.10 & 16.17 \\
14 & $80-10-8-90$ & 16.70 & 17.47 \\
15 & $40-60-8-90$ & 15.00 & 15.18 \\
16 & $80-60-8-90$ & 16.50 & 16.48 \\
17 & $20-35-4.5-60$ & 18.20 & 18.20 \\
19 & $60-10-4.5-60$ & 18.40 & 18.48 \\
21 & $60-35-1-60$ & 16.30 & 16.66 \\
25 & $60-35-4.5-60$ & 18.50 & 18.31 \\
26 & $60-35-4.5-60$ & 19.20 & 18.31 \\
27 & $60-35-4.5-60$ & 17.20 & 18.31 \\
28 & $60-35-4.5-60$ & 18.50 & 18.31 \\
29 & $60-35-4.5-60$ & 17.70 & 18.31 \\
30 & $60-35-4.5-60$ & 19.20 & \\
\hline
\end{tabular}

Note: Experimental condition, 60-35-4.5-60 is read as; $60 \%(\mathrm{v} / \mathrm{v})$ acetone concentration, at a temperature of $35^{\circ} \mathrm{C}$, $4.5 \%(\mathrm{w} / \mathrm{v})$ solid-to-solvent ratio for 60 minutes' extraction time

3.3.2 Response Surface Plots for Total Phenolic Content and Fraction of Solids Solubilised

Three dimensional plots (3D) showing the effects of two independent factors whilst keeping other two at mean values on the total phenolic content and fraction of solids solubilised are represented in Figures 8 and 9. 

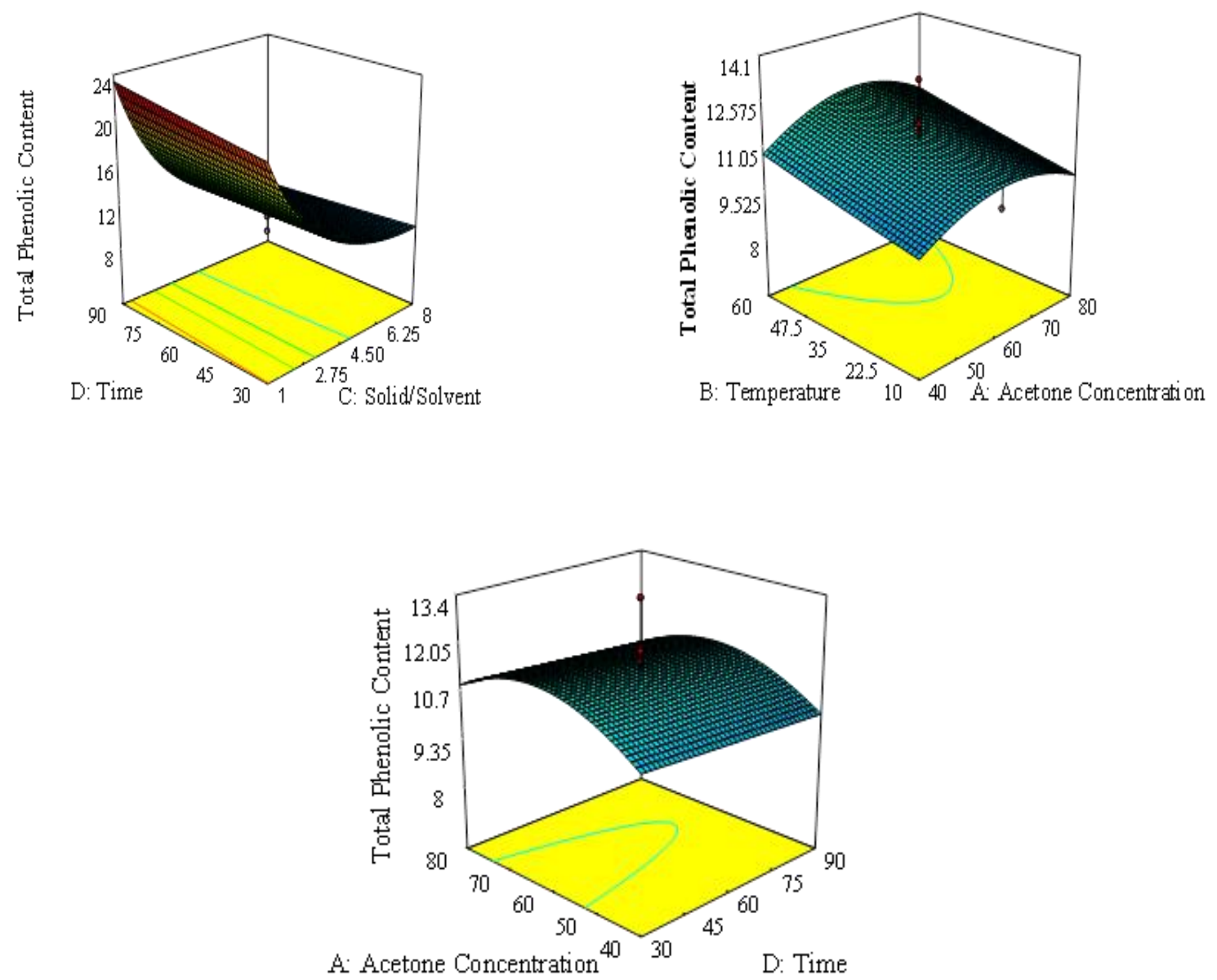

Figure 8. Effects of acetone concentration $\%(\mathrm{v} / \mathrm{v})$, temperature $\left({ }^{\circ} \mathrm{C}\right)$, solid-to solvent ratio $\%(\mathrm{w} / \mathrm{v})$, time (minutes) on total phenolic content (mg GAE /g dw) for varying 2 factors whilst maintain other 2 at mean values used in design 

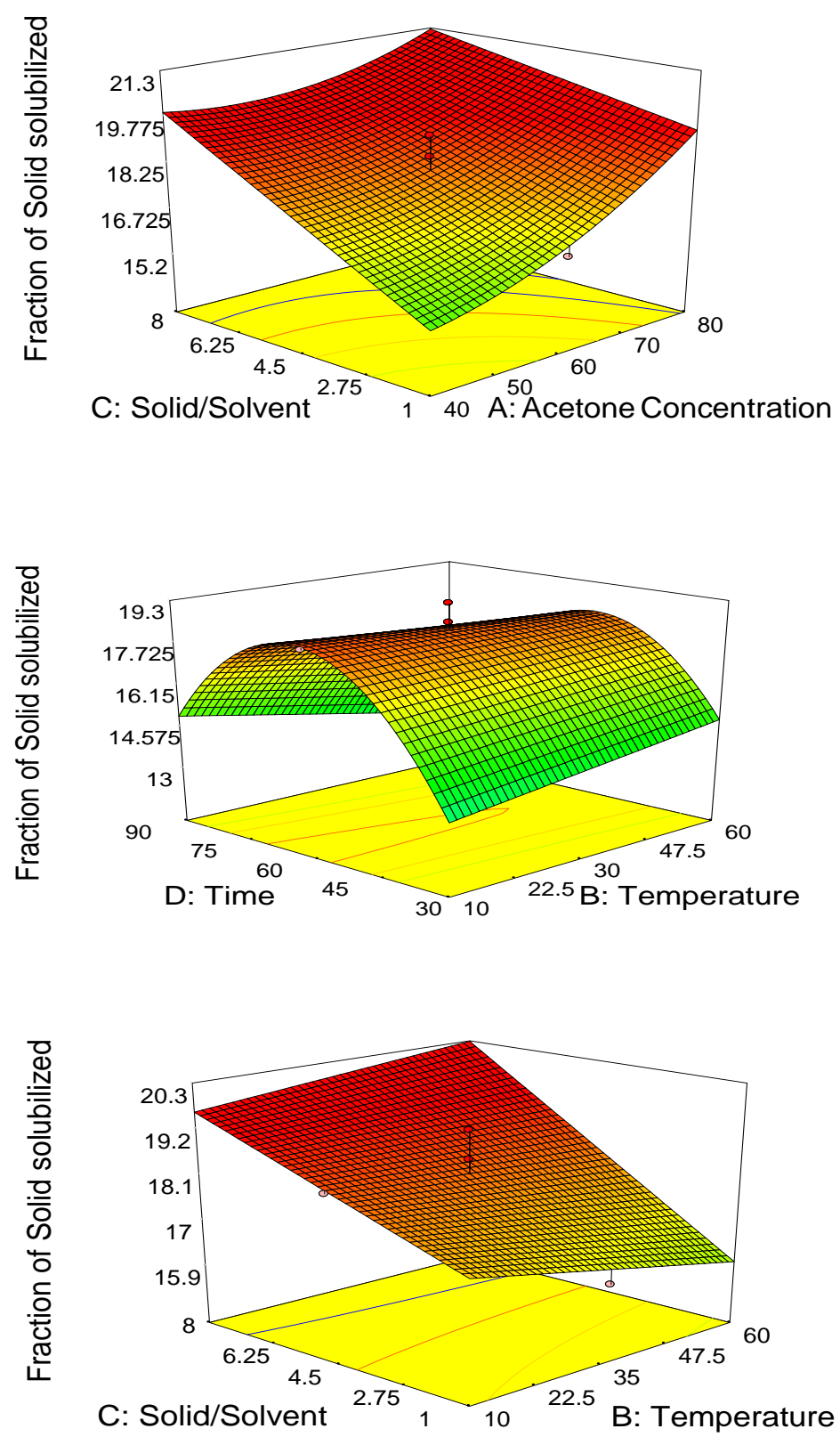

Figure 9. Effects of solid-to-solvent ratio (\%w/v), acetone concentration $\%(\mathrm{v} / \mathrm{v})$, temperature $\left({ }^{\circ} \mathrm{C}\right)$, on fraction of solids solubilised $(\mathrm{g} / 100 \mathrm{~g})$ for varying 2 factors whilst maintain other 2 at mean values used in design

Total phenolic content increases with acetone concentration, temperature increases initially and decreases significantly when acetone concentration was above $70 \%$ with increasing solid-to solvent ratio.

\subsubsection{Optimisation of Process and Verification of Model for Total Phenolic Content}

Optimal conditions were obtained using the transformed quadratic model with the objective to achieve maximum total phenolic content from apple pomace. The conditions for the optimisation were set using the numerical optimisation and the design expert generated series of solutions with varying desirability. Conditions with highest value of desirability was selected and extractions were carried out in three replicates and total phenolic content determined and the results shown in Table 8. 
Table 8. Optimal conditions for Total phenolic content under Acetone Extraction

\begin{tabular}{llllll}
\hline & \multicolumn{2}{c}{ Optimal Conditions } & & \multicolumn{2}{c}{ Total Phenolic Content } \\
\hline Acetone & Extraction & Solid/Solvent & Extraction & Predicted & Actual \\
Conc. & Temp & ratio & Time & TPC & TPC \\
$(\%)$ & ${ }^{\circ} \mathrm{C}$ & $(\%)$ & $(\mathrm{min})$ & $\mathrm{mgGAE} / \mathrm{g} \mathrm{dw}$ & $\mathrm{mgGAE} / \mathrm{g} \mathrm{dw}$ \\
\hline 65 & 60 & 1 & 30 & 21.35 & $21.70 \pm 0.2$ \\
\hline
\end{tabular}

The results showed no significant difference between the experimental values and the values predicted for total phenolic content of the aqueous acetone extracts. Therefore, the statistical method could be used to predict phenolic content of apple pomace by response surface methodology within the parameters. Hence total phenolic content of $21.7 \mathrm{mg}$ GAE /g $\mathrm{dw}$ was recovered from the apple pomace. Total phenolic content of $21.75 \mathrm{mg} \mathrm{GAE} / \mathrm{g} \mathrm{dw}$ and $27.04 \mathrm{mg} \mathrm{GAE} / \mathrm{g} \mathrm{dw}$ have previously been recovered from oven and freeze dried apple pomace respectively using $80 \%$ (v/v) acetone (Laura et al., 2013). Optimum total phenolic content of $14.15 \mathrm{mg}$ GAE/g dw using $65 \%$ aqueous acetone at $25^{\circ} \mathrm{C}$ for 60 minutes had been reported (Wijngaard and Brunton, 2010). Aqueous acetone, $70 \%$ at $20^{\circ} \mathrm{C}$ was used by Suarez et al., and recorded $6.48 \mathrm{mg} \mathrm{GAE} / \mathrm{g}$ dw (Suarez et al., 2010).

\section{Response surface plots for Fraction of Solids Solubilised under Acetone Extraction}

Response surface plots for fraction of solids solubilised from the acetone extracts for the various combinations of design parameters are shown in Figure 9.

Solubility of solids in solvents depended on the activity coefficient which changes with temperature and has the capacity to modify activity coefficient. Fraction of solids solubilised increases linearly with temperature and solid-to solvent ratio and decreases drastically at higher temperatures with extended extraction time. Positive coefficient of acetone concentration in the quadratic term describes the curvature of the response plots in whose increment positively impacted on faction of solids solubilised.

\subsubsection{Optimisation of Process and Verification of Model for Fraction of Solids Solubilised}

Optimised conditions were obtained from the many solutions generated by the design expert as in the case similar to total phenolic content. Conditions with the highest desirability were selected and extractions were carried out in three replicates and fraction of solids solubilised determined and shown in Table 9.

Table 9. Optimal conditions for Fraction of solids solubilised under Acetone Extraction

\begin{tabular}{llllll}
\hline $\begin{array}{c}\text { Optimal } \\
\text { Fraction of solids solubilised }\end{array}$ & & & & Conditions \\
\hline Acetone & Extraction & Solid/solvent & Extraction & Predicted & Actual \\
Conc. & Temp & ratio & time & & \\
$(\%)$ & $(\%)$ & $(\mathrm{min})$ & $\mathrm{g} / 100 \mathrm{~g}$ & $\mathrm{~g} / 100 \mathrm{~g}$ \\
\hline 78 & 21 & 4.7 & 54 & 19.92 & $19.20 \pm 0.1$ \\
\hline
\end{tabular}

\subsection{Separation and Identification of Phenolic Compounds in Acetone Extracts}

The phenolic compounds were identified using their respective retention times (tR) and spectra data of known complimentary phenolic standards at their maximum absorbance stored in the library of the HPLC ChemStation. The phenolic compounds identified were Chlorogenic acid, Caffeic acid Phloridzin, Procyanidin B2, Epicatechin, Quercetin -3-galactoside and Quercetin-3-glucoside. These compounds were identified in commercial apple pomace and documented in literature (Schieber et al., 2001, Çam and Aaby, 2010, Diñeiro García et al., 2009, Suarez et al., 2010). The retention times of the Phenolic compounds used for the identification are shown in Table 10. Typical chromatogram of the phenolic compounds at $320 \mathrm{~nm}$ is shown in Figure 10.

Quercetin glycosides which were thought to be very difficult to separate because they related closely (Tsao and McCallum, 2009), were well resolved by the method. Additionally, 3 other quercetin glycosides were resolved but standards were not readily available for their identification. These quercetin glycosides could be quercetin -3-xyloside, quercetin-3- arabinoside and quercetin-3-O-rhamnoside according to elution order (Schieber et al., 2001, Serena et al., 2007). Phloridzin, Epicatechin and Procyanidin B2 were detected at $280 \mathrm{~nm}$, and Chlorogenic and Caffeic acids at $320 \mathrm{~nm}$, and quercetin glycosides at $370 \mathrm{~nm}$. 


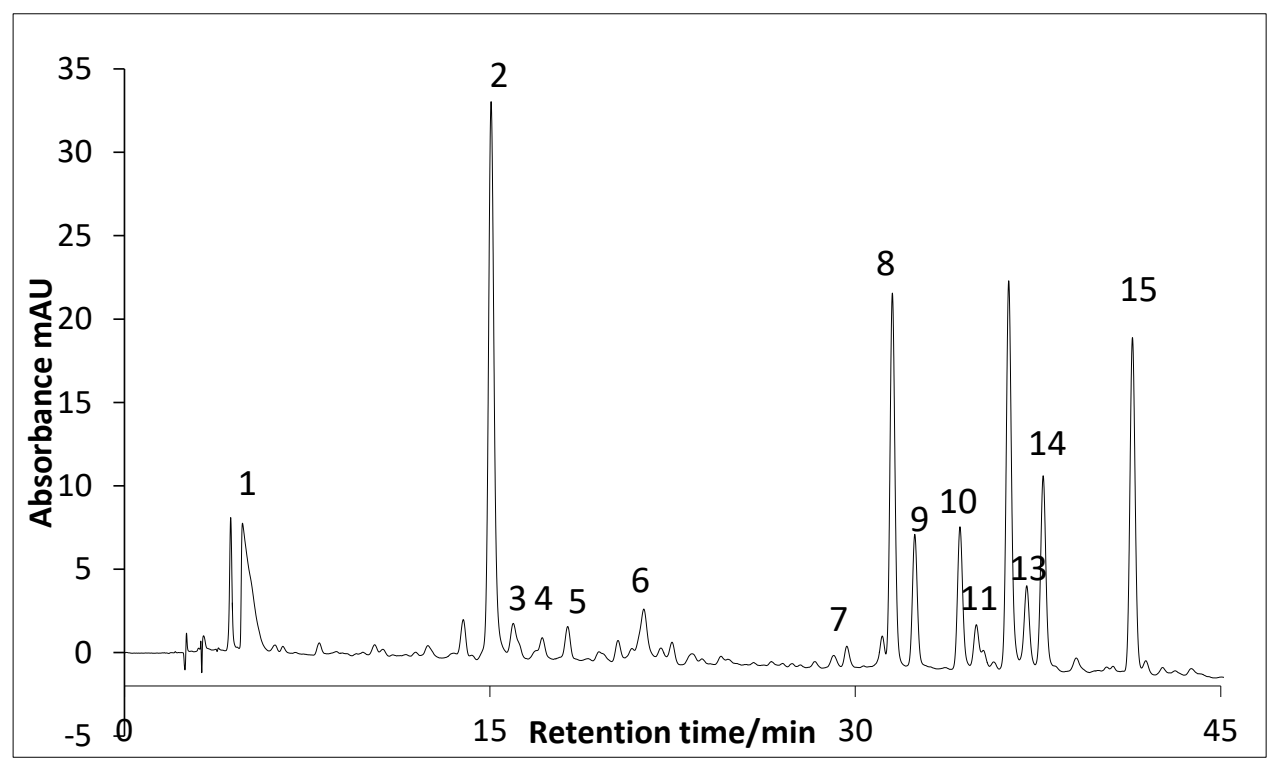

Figure 10. Chromatogram of phenolic compounds isolated from the apple pomace using aqueous acetone. $1=$ acetone, 2=chlorogenic acid, 3= procyanidin B2, 4= caffeic acid, 5= epicatechin, 7-Ferulic acid, 8= quercetin-3-galactoside, $9=$ quercetin-3-glucoside, $15=$ phloridzin at $320 \mathrm{~nm}$

Table 10. Retention time of selected Phenolic standards

\begin{tabular}{ll}
\hline Phenolic standard & Retention time (min) \\
\hline 5-HMF & $7.3 \pm 0.05$ \\
Furfural & $10.4 \pm 0.06$ \\
Protocatechuic aldehyde & $12.4 \pm 0.06$ \\
Catechin & $13.03 \pm 0.01$ \\
Chlorogenic acid & $15.17 \pm 0.05$ \\
Procyanidin B2 & $16.13 \pm 0.07$ \\
Caffeic acid & $17.5 \pm 0.08$ \\
Epicatechin & $18.6 \pm 0.07$ \\
P-Coumaric acid & $25.3 \pm 0.08$ \\
Ferulic acid & $29.3 \pm 0.20$ \\
Quercetin- 3- galactoside & $31.47 \pm 0.11$ \\
Quercetin -3-glucoside & $32.4 \pm 0.01$ \\
Phloridzin & $41.5 \pm 0.23$ \\
Phloretin & $50.32 \pm 0.12$ \\
Quercetin & $57 \pm 0.25$ \\
\hline
\end{tabular}

\section{Conclusions}

Results have shown that, the recovery of polyphenolic compounds from industrial apple pomace depended on the solvent type, solvent concentration, solid to solvent ratio, temperature and resident time. Optimal conditions of extracting phenolic compounds were as follows: acetone concentration, $65 \%(\mathrm{v} / \mathrm{v})$; solid to Solvent ratio $1 \%$; extraction time 30 minutes and temperature $60{ }^{\circ} \mathrm{C}$ and those for solubilisation of the biomass was: acetone concentration $78 \%$ (v/v); solid to solvent ratio $4.7 \%$; extraction time 54 minutes and temperature $21^{\circ} \mathrm{C}$. Clearly optimal conditions for extracting polyphenolic compounds varied from conditions for solubilisation as it was not only polyphenolic compounds that were eluted. Under these conditions, the optimal total phenolic content and solubilisation were $21.70 \pm$ $0.2 \mathrm{mg} \mathrm{GAE} / \mathrm{g} \mathrm{dw}$ and $19.20 \pm 0.1 \mathrm{~g} / 100 \mathrm{~g}$ of the dried apple pomace respectively. Therefore, statistical tools could be used to design an experiment to study the interrelationship between experimental factors and to predict the region of optimum response. Designed conditions demonstrated selectivity towards significant recovery of polyphenolic content 
and overall solubilisation of the apple pomace. The major polyphenolic compounds in the apple pomace were chlorogenic acid, procyanidin B2, caffeic acid, epicatechin, ferulic acid, quercetin-3-galactoside, quercetin-3-glucoside and phloridzin.

\section{Acknowledgement}

The authors greatly acknowledge Ghana Education Trust Fund (GETFund) for financial support and Universal Beverages Limited (UBL), UK for supplying the apple pomace sample.

\section{References}

Allison, P. (2012). When Can You Safely Ignore Multicollinearity? [online]. http://statisticalhorizons.com/ Statistical Horizon [Accessed

Arranz, S., Silván, J. M., \& Saura-Calixto, F. (2010). Nonextractable polyphenols, usually ignored, are the major part of dietary polyphenols: a study on the Spanish diet. Molecular nutrition \& food research, 54(11), 1646-1658. https://doi.org/10.1002/mnfr.200900580

Bai, X. L., Yue, T. L., Yuan, Y. H., \& Zhang, H. W. (2010). Optimization of microwave-assisted extraction of polyphenols from apple pomace using response surface methodology and HPLC analysis. Journal of Separation Science, 33, 3751-3758. https://doi.org/10.1002/jssc.201000430

Bhushan, S., Kalia, K., Sharma, M., Singh, B., \& Ahuja, P. S. (2008). Processing of apple pomace for bioactive molecules. Critical Reviews in Biotechnology, 28, 285-296. https://doi.org/10.1080/07388550802368895

Çam, M., \& Aaby, K. (2010). Optimization of Extraction of Apple Pomace Phenolics with Water by Response Surface Methodology. Journal of Agricultural and Food Chemistry, 58 (16), 9103-9111. https://doi.org/10.1021/jf1015494

Cetkovic, G., Canadanović-Brunet, J., Djilas, S., Savatović, S, Mandić, A., \& Tumbas, V. (2008). Assessment of polyphenolic content and in vitro antiradical characteristics of apple pomace. Food Chemistry, 109(2), 340-347. https://doi.org/10.1016/j.foodchem.2007.12.046

Chantanta, D. K., Attri, C., Gopal, K., Devi, M., Gupta, G., \& Bhalla, T. C. (2008). Bioethanol production from applepomace left after juice extraction. Internet Journal of Microbiolog, 5(2). https://doi.org/10.5580/3a8

Chen, F., Sun, Y., Zhao, G., Liao, X., Hu, X., Wu, J., \& Wang, Z. (2007). Optimization of ultrasound-assisted extraction of anthocyanins in red raspberries and identification of anthocyanins in extract using high-performance liquid chromatography-mass spectrometry. Ultrasonics Sonochemistry, 14(6), 767-778. https://doi.org/10.1016/j.ultsonch.2006.12.011

Crozier, A., Jaganath, I. B., \& Clifford, M. N. (eds.) (2006). Phenols, Polyphenols and Tannins: An Overview. Oxford, UK,: Blackwell Publishing Ltd.

Cruz, A. G., Scullin, C., Mu, C., Cheng, G., Stavila, V., Varanasi, P., ... Singh, S. (2013). Impact of high biomass loading on ionic liqu.id pretreatment. Biotechnology for biofuels, 6(1), 1-10. https://doi.org/10.1186/1754-6834-6-52

Dai , J., \& Mumper, R. J. (2010). Plant Phenolics: Extraction, Analysis and their Antioxidant and Anticancer Properties. Molecules, 15, 7313-7352. https://doi.org/10.3390/molecules15107313

Diñeiro, G. Y., Valles, B. S., \& Picinelli, L. A. (2009). Phenolic and antioxidant composition of by-products from the cider industry: Apple pomace. Food Chemistry, 117(4), 731-738. https://doi.org/10.1016/j.foodchem.2009.04.049

Foo, L. Y., \& Lu, Y. (1999). Isolation and identification of procyanidins in apple pomace. Food Chemistry, 64(4), 511-518. https://doi.org/10.1016/S0308-8146(98)00150-2

Hair, J. F. J., Anderson, R. E., \& Tatham, R. L. (1995). Multivariate Data Analysis (3rd ed). New York: Macmillan.

Harborne, J. (1993). The flavonoids: Advances in research since 1986. London: Chapman and Hall.

Heinonen, I. M., Meyer, A. S., \& Frankel, E. N. (1998). Antioxidant activity of berry phenolics on human low-density lipoprotein and liposome oxidation.Journal of Agricultural and Food Chemistry, 46(10), 4107-4112. https://doi.org/10.1021/jf980181c

Hismath, I., Wan Aida, W., \& Ho, C. (2011). Optimization of extraction conditions for phenolic compounds from neem (Azadirachta indica) leaves. International Food Research Journal, 18(3).

Hollman, P. C., van Trijp, J., Buysman, M. N., van der Gaag, M. S., Mengelers, M. J., de Vries, J. H., \& Katan, M. B. (1997). Relative bioavailability of the various antioxidant flavonoid quercetin from various foods in man. FEBS Let., 418(1-2), 152-156. https://doi.org/10.1016/S0014-5793(97)01367-7 
Joshi, V. K., \& Attri, B. L. (1991). Importance and scope of fruit based fermented beverages in India. Beverage and Food World, 17(4), 9-10.

Joshi, V. K., \& Attri, D. (2006). Solid state fermentation of apple pomace for the production of value added products. Natural Product Radiance, 5(4), 289-296.

Kahkonen, M. P., Hopia, A. I., \& Heinonen, M. (2001). Berry phenolics and their antioxidant activity Journal of Agricultural and Food Chemistry, 49(8), 4076-4082. https://doi.org/10.1021/jf010152t

Kennedy, M., List, D., Lu, Y., Newman, R. H., Sims, I. M, Bain, P. J. S., Hamilton, B., \& Fenton, G. (1999). Apple pomace and products derived from apple pomace: Uses, composition and analysis. Berlin: Heidelberg: Springer. https://doi.org/10.1007/978-3-662-03887-1_4

Klein-Marcuschamer, D., Simmons, B. A., \& Blanch, H. W. (2011). Techno-economic analysis of a lignocellulosic ethanol biorefinery with ionic liquid pre-treatment. Biofuels, Bioproducts and Biorefining, 5(5), 562-569. https://doi.org/10.1002/bbb.303

Knekt, P., Järvinen, R., Seppänen, R., Hellövaara. M., Teppo, L., Pukkala, E., \& Aromaa, A. (1997). Dietary flavonoids and the risk of lung cancer and other malignant neoplasms American Journal of Epidemiology, 146(3), 223-30. https://doi.org/10.1093/oxfordjournals.aje.a009257

Laura, M., Daniel, R., Ana, B. M. D., \& Catherine, B. R. (2013). Valorisation of Apple Peels. European Journal of Food Research \& Review, 3(1), 1-15.

Liang, X., \& Fan, Q. (2013) Application of Sub-Critical Water Extraction in Pharmaceutical Industry. Journal of Materials Science and Chemical Engineering, 1(5), 6. https://doi.org/10.4236/msce.2013.15001

Liu, R. H. (2003). Health benefits of fruits and vegetables are from additive and synergistic combination of phytochemicals. The American journal of clinical nutrition, 78(3), 517-520. https://doi.org/10.1093/ajcn/78.3.517S

Liyana-Pathirana, C., \& Shahidi, F. (2005). Optimization of extraction of phenolic compounds from wheat using response surface methodology. Food Chemistry, 93(1), 47-56. https://doi.org/10.1016/j.foodchem.2004.08.050

Lu, Y., \& Foo, L. Y. (1997). Identification and quantification of major polyphenols in apple pomace. Food Chemistry, 59(2), 187-194. https://doi.org/10.1016/S0308-8146(96)00287-7

Lu, Y., \& Foo, L. Y. (2000). Antioxidant and radical scavenging activities of polyphenols from apple pomace and vegetables. Food Chemistry, 68(1), 81-85. https://doi.org/10.1016/S0308-8146(99)00167-3

Luthria, D. L. (2006). Significance of sample preparation in developing analytical methodologies for accurate estimation of bioactive compounds in functional foods. Journal of the Science of Food and Agriculture, 86, 2266-2272. https://doi.org/10.1002/jsfa.2666

Manach, C., Scalbert, A., Morand, C., Rémésy, C., \& Jiménez, L. (2004). Polyphenols: food sources and bioavailability. American Journal of Clinical Nutrition, 79, 727-747. https://doi.org/10.1093/ajcn/79.5.727

Pacheco-Palencia, L. A., Duncan, C. E., \& Talcott, S. T. (2009). Phytochemical composition and thermal stability of two commercial açai species, Euterpe oleracea and Euterpe precatoria. Food Chemistry, 115(4), 1199-1205. https://doi.org/10.1016/j.foodchem.2009.01.034

Reis, S. F., Rai, D. K., \& Abu-Ghannam, N. (2012). Water at room temperature as a solvent for the extraction of apple pomace phenolic compounds. Food Chemistry, 135, 1991-1998. https://doi.org/10.1016/j.foodchem.2012.06.068

Rogerson, P. (2001) Statistical methods for geography. Sage Publications Ltd. ISBN-10: 0761962875. https://doi.org/10.4135/9781849209953

Saura-Calixto, F., Serrano, J., \& Goñi, I. (2007). Intake and bioaccessibility of total polyphenols in a whole diet. Food Chemistry, 101, 492-501. https://doi.org/10.1016/j.foodchem.2006.02.006

Schieber, A., Keller, P., \& Carle, R. (2001). Determination of phenolic acids and flavonoids of apple and pear by high-performance liquid chromatography. Journal of Chromatography A, 910, 265-273. https://doi.org/10.1016/S0021-9673(00)01217-6

Serena, C. M., William, M., \& Crozier, A. (2007). Flavonoids and Chlorogenic acid profiles of English cider apples. Journal of the Science of Food and Agriculture, 87, 719-728. https://doi.org/10.1002/jsfa.2778

Shari, K. (2013). How to get Started with Design- Expert Software. In Stat-Ease (Ed.) www.statease.com/webinar.html.

Silva, E., Rogez, H., \& Larondelle, Y. (2007). Optimization of extraction of phenolics from Inga edulis leaves using response surface methodology. Separation and Purification Technology, 55(3), 381-387. 
https://doi.org/10.1016/j.seppur.2007.01.008

Sivaraman, T., Kumar, T. K. S., Jayaraman, G., \& Yu, C. (1997). The Mechanism of 2,2,2-Trichloroacetic Acid-Induced Protein Precipitation. Journal of Protein Chemistry, 16(4), 291-297. https://doi.org/10.1023/A:1026357009886

Suarez, B., Ángel L. Álvarez, Yolanda Diñeiro García , de Barrio, G. Lobo, A. P., \& Porra, F. (2010). Phenolic profiles, antioxidant activity and in vitro antiviral properties of apple pomace. Food Chemistry, 120, 339-342. https://doi.org/10.1016/j.foodchem.2009.09.073

Sun, J., Chu, Y. F., Wu, X., \& Liu, R. H. (2002). Antioxidant and antiproliferative activities of common fruits. Journal of Agricultural and Food Chemistry, 50(25), 7449-7454. https://doi.org/10.1021/jf0207530

Tsao, R., \& McCallum, J. (2009). Chemistry of Flavonoids. In ; Eds.; Blackwell Publishing: USA: Ames, IA.

Vasil'ev, Y. I., Morozov, A. N., Zaiko, G. M., \& Moiseeva, V. G. (1976). The utilization of waste from vegetable and fruit canning plants. Konservnaya-i-Ovoshchesushil naya-Promyshlennost, 3, 32-34.

Vinson, J. A., Su, X., Zubik, L., \& Bose, P. (2001). Phenol antioxidant quantity and quality in foods: fruits. Journal of Agricultural and Food Chemistry, 49, 5315-5321. https://doi.org/10.1021/jf0009293

Waterhouse, A. L. (2001). Determination of Total Phenolics. Current Protocols in Food Analytical Chemistry, John Wiley \& Sons, Ltd.

Wijngaard, H. H., \& Brunton, N. (2009). The optimization of extraction of antioxidants from apple pomace by pressurized liquids. Journal of Agricultural and Food Chemistry, 57(22), 10625-10631. https://doi.org/10.1021/jf902498y

Wijngaard, H. H., \& Brunton, N. (2010). The optimisation of solid-liquid extraction of antioxidants from apple pomace by response surface methodology. Journal of Food Engineering, 96(1), 134-140. https://doi.org/10.1016/j.jfoodeng.2009.07.010

\section{Copyrights}

Copyright for this article is retained by the author(s), with first publication rights granted to the journal.

This is an open-access article distributed under the terms and conditions of the Creative Commons Attribution license (http://creativecommons.org/licenses/by/4.0/). 